\title{
Uso y abuso de la religión en la geoestrategia política de Cleómenes I
}

\author{
Use and Abuse of Religion in the Political Geostrategy of Cleomenes I
}

Recibido: 25-11-2019. Aceptado: 27-01-2020.

\begin{abstract}
Resumen
El reinado de Cleómenes I ha sido tradicionalmente considerado como el punto de partida de la política expansionista de Esparta más allá de las fronteras del Peloponeso. Para llevar a cabo sus objetivos, el diarca utilizó audazmente el recurso a la religión, sirviéndose especialmente de las profecías emitidas por el oráculo de Delfos. Sus fallidas campañas contra Atenas, el ataque que ejecutó contra Argos o las intrigas políticas que fomentó fueron aspectos convenientemente respaldados por justificaciones de índole mística. Admirado y denostado por diferentes sectores de la historiografía moderna, Cleómenes constituye una turbulenta figura de la historia de Esparta cuya muerte está rodeada de un halo de misterio. A través de las fuentes antiguas, entre las que destaca el halicarnasio Heródoto, este artículo analizará hasta qué punto este polémico personaje se sirvió de la religión y las posibles razones que subyacían bajo la agresiva política espartana de finales del siglo VI e inicios del V a. C., así como las maniobras del rey en el seno de la clase dirigente espartiata para imponerse sobre sus adversarios políticos.
\end{abstract}

\footnotetext{
Abstract

The reign of Cleomenes I has traditionally been considered as the starting point of Sparta's expansionist policy beyond the borders of the Peloponnese. To accomplish his objectives, the dyarch made a boldly use of religion, exploiting especially the prophecies issued by the Delphic oracle. Events like the failed campaigns against Athens, the attack on Argos, or the political intrigues Cleomenes I promoted were all conveniently supported by mystical justifications. Equally admired and reviled by modern historiography, Cleomenes I is a turbulent figure in the history of Sparta whose death is surrounded by mystery. Using a number of ancient sources, among which Herodotus of Halicarnassus stands out, this paper will analyse to what extent this controversial figure made use of religion, the reasons that motivated the aggressive Spartan policy (noticeable since late VI to early V century BC), as well as the tactics employed by the king in order to prevail over political adversaries within the Spartan ruling class.
}

Palabras clave Esparta Cleómenes 1 Delfos oráculos Atenas

Keywords

Sparta Cleomenes I Delphi oracles Athens 
1. Para profundizar en el ordenamiento conocido como Gran Retra, véase Nafissi (2010, pp. 91-93; 2018, pp. 93-123); Fornis (2016, pp. 57-76); Murcia Ortuño (2017, pp. 67-71).
2. Cartledge (1979, pp. 123-124) indica que Cleómenes I fue sin duda el rey espartano más poderoso desde Polidoro.
Una de las constantes que, históricamente, han caracterizado a las sociedades organizadas ha sido la relación que, en todas ellas, se ha forjado entre quienes ostentan el poder y los agentes místicos o religiosos. No es irracional suponer que, desde tiempos inmemoriales, los órganos de autoridad de los diversos Estados establecieron una rentable simbiosis con las instituciones religiosas existentes que permitieron a los primeros beneficiarse política, económica y socialmente de las coyunturas propiciadas por los segundos. Este factor cobró especial relevancia en la Antigüedad, en la que las identidades que progresivamente fueron surgiendo necesitaron dotarse de un relato mítico-legendario que contribuyese a erradicar los conflictos que, por lo general, se derivaban de su distinción en clases, una versión etnogenética que se caracterizó por la tendencia a fusionar a líderes y dioses.

En el caso de la antigua Grecia el ejemplo más paradigmático de mutua rentabilidad entre dirigentes estatales y religiosos lo constituyó la polis de Esparta. Su ordenamiento político, emanado de la Gran Retra, estableció un entramado institucional prácticamente inamovible como consecuencia de la vinculación de la politeía espartana con el oráculo de Delfos (Plu., Lyk., 6; Tyr. 3 Diehl)1, la voz de Apolo procedente de uno de los santuarios panhelénicos más importantes de la Hélade (Scott, 2015, pp. 27-78). Es lógico, por tanto, que los diarcas, como representantes de una entidad política asimismo sancionada por la pitia délfica, se preocuparan por fortalecer los nexos de su ciudad con este centro religioso para utilizar convenientemente las profecías resultantes. En este sentido, uno de los mayores exponentes del uso instrumental de la religión, en Esparta en particular y en Grecia en general, fue el agíada Cleómenes I, dinasta lacedemonio entre el 520 y el 490 a. C. sobre el que la doctrina historiográfica vierte opiniones que oscilan entre quienes lo califican de excelente dirigente y los que, por el contrario, lo tachan de gobernante maníaco (Fornis, 2016, p. 100). El presente artículo tiene como objetivo analizar hasta qué punto este polémico soberano se benefició del recurso a la religión y cómo el oráculo de Delfos, como una de las entidades religiosas más importantes de Grecia, influyó en la política interior y exterior espartana durante su reinado, enmarcado en las últimas décadas del Arcaísmo griego e inmediatamente anterior al conflicto contra el Imperio persa. Para lograr el objetivo de este estudio se hará especial hincapié en los testimonios que nos ofrecen los autores antiguos, a los que debemos sumar estudios especializados de la historiografía moderna, todo ello para demostrar que las profecías délficas supusieron un factor decisivo en el progreso (o en el fracaso) de Esparta, encabezado por Cleómenes en el paso del siglo VI a V a. C.

La vida política de Cleómenes fue tumultuosa desde su ascensión al trono. Fruto del matrimonio del también agíada Anaxándridas II y de su segunda esposa, el nuevo diarca contaba con tres hermanastros nacidos de la primera mujer de su predecesor que, por este motivo, podrían esgrimir un mayor derecho a la sucesión. Parece que las autoridades encargadas de nombrar al sustituto pasaron por alto las razones en torno al linaje y Cleómenes, en tanto que hijo primogénito de Anaxándridas, o quizá en razón de una presunta habilidad marcial superior a la de sus competidores, fue entronizado ${ }^{2}$. Sea como fuere, la decisión enemistó inmediatamente al nuevo diarca con Dorieo, uno de sus hermanastros que pretendía el trono bajo el pretexto de ser vástago de la primera mujer del anterior diarca y que, según la tradición, decidió poner tierra de por medio. El relato de Heródoto, sobre el que merece la pena detenerse, describe cómo Dorieo, "negándose a ser gobernado por Cleómenes, solicitó de los espartanos un grupo de ciudadanos y se los llevó a fundar una colonia sin consultar el oráculo de Delfos" (Hdt., 5, 42, 2). La negativa del pretendiente a llevar a cabo los pertinentes procedimientos en Delfos cobra importancia si tenemos en cuenta que el proceso colonizador griego estuvo vertebrado por el oráculo, hasta tal punto que existía una creencia que asociaba el éxito de la empresa con la visita a la sacerdotisa de Apolo (cfr. Malkin, 1987, pp. 78-81). 
Así se fundó el asentamiento de Cínipe, en la costa septentrional de la actual Libia, en un acto privado que, obviamente, no gozó del patrocinio de la Esparta de Cleómenes ${ }^{3}$. Heródoto continúa su arco narrativo explicando que, dos años después del levantamiento del nuevo poblado, Dorieo y los suyos "fueron expulsados del lugar por los cartagineses y los libios, y regresaron al Peloponeso" (Hdt., 5, 42, 3). De vuelta en su patria, Dorieo recibió el consejo de reclamar el territorio del monte Érice, en la isla de Sicilia: según unas profecías, pertenecía a los descendientes de los Heraclidas dado que Heracles, de acuerdo con el mito, lo poseyó en su día ${ }^{4}$. En esta ocasión, Dorieo sí llevó a cabo la pertinente consulta a la pitia de Delfos. Así lo recogió el historiador de Halicarnaso (Hdt., 5, 43, 1):

\section{Al oír esto, Dorieo se encaminó a Delfos para preguntar al oráculo si lograría apo- derarse de la comarca a la que pensaba dirigirse; y la pitia le respondió que ocupa- ría la tierra de Sicilia. Entonces Dorieo volvió a hacerse cargo del contingente de colonos que había conducido a Libia y se trasladó a Italia.5}

Con este vaticinio délfico, prosigue Heródoto, se fundó Heraclea en el noroeste siciliano. Pese a la bendición apolínea, quiso el destino que Dorieo y la mayor parte de sus seguidores murieran poco después, en una escaramuza contra nativos de la zona, después de que los espartiatas asentados allí se entrometieran en la guerra que mantenían sibaritas, crotoniatas y sus respectivos aliados ${ }^{7}$. Se cumplía, de este modo tan taimado, la predicción pítica que afirmaba que Dorieo "ocuparía la tierra de Sicilia", toda vez que su cadáver descansó en esa isla.

Con la desaparición de Dorieo se desvanecieron las preocupaciones políticas de su hermanastro Cleómenes en lo que a las pretensiones sobre el trono agíada se refería. No obstante, la narración que nos ofrece Heródoto fue compilada casi un siglo después (en torno al año 440 a. C.), un lapso de tiempo más que suficiente para que, a expensas del diarca, se construyera un relato que enlazase la muerte de Dorieo con los deseos del oráculo de Delfos que, a su vez, cumpliría los designios de Apolo pítico al eliminar los elementos que amenazaran al auténtico rey, descendente de Heracles. A la incertidumbre en torno a la muerte de Dorieo, fechada en el 510 a. C. (Fornis, 2016, p. 101), habría que añadir que la localización exacta del enclave donde se levantó Heraclea continúa siendo una incógnita (Hansen y Nielsen, 1994, p. 197). En cualquier caso, la legitimidad y el liderazgo de Cleómenes quedaron apuntalados por los, ficticios o no, oráculos del santuario de Delfos.

Antes, incluso, de que se desvaneciera la amenaza que suponía la mera existencia de Dorieo, Delfos ya marcó la política exterior espartana de Cleómenes. A finales del siglo VI a. C., Atenas comenzó a despuntar en el panorama geopolítico de la antigua Grecia, lo que, unido a las diferencias en los regímenes políticos de ambas poleis (la Gran Retra espartana y la tiranía establecida en Atenas), suscitó tensiones que se agravaron con el paso del tiempo y que desembocaron en varias expediciones militares lacedemonias dirigidas por el diarca.

Para entender las intromisiones de Cleómenes en el Ática y el papel desempeñado por Delfos en las mismas, debemos retrotraernos hasta los primeros años de la década de los 30 del siglo VII, cuando se produjo el acontecimiento conocido como "conjura de Cilón", personaje de noble cuna que perpetró un golpe de estado en Atenas que no prosperó ${ }^{8}$. Fracasada su intentona, Cilón y sus partidarios se refugiaron en el santuario de la acrópolis, lugar sagrado donde imperaba la prohibición de derramar sangre. Los magistrados atenienses, conocidos como "prítanos de los naucraros" consiguieron que el instigador y sus seguidores abandonaran el recinto religioso con la promesa de respetar sus vidas, pero fueron asesinados por orden de Megacles, el arconte polemarco, miembro de la aristocrática familia de los Alcmeónidas, la cual
3. Se ha especulado con la posibilidad de que los viajes colonizadores de Dorieo fueran parte de un complejo programa expansionista espartano a través de las costas del Mediterráneo occidental, con la intención de afianzar los intereses lacedemonios ante el peligro derivado del control de los mares por parte de Cartago y Persia. Así también Huxley (1962, pp. 78-79) y Braccesi (1999). En cambio, Von Stauffenberg (196o, pp. 185-186) concluye que la diarquía, la Gerousía u otras autoridades espartanas no promovieron la aventura. Forrest (1968, p. 65) también considera que el viaje a las costas libias fue consecuencia de las motivaciones personales de Dorieo. Para Fornis (2016, p. 101), "no parece existir base suficiente para enmarcar estas correrías de Dorieo en un genuino diseño estratégico de expansión por el Occidente alentado desde Esparta".

4. El consejo habría sido otorgado por un adivino de nombre Antícares de Eleón, de quien únicamente sabemos que estaba en poder de ciertos oráculos, según Huxley (1983, p. 7). Heródoto 5, 43, 1, nos informa de que Eleón se encuentra en Beocia, pero no aporta información acerca del adivino.

5. Las traducciones herodoteas son obra de Manuel Balasch (1999).

6. Paus., 3, 16, 5, hace alusión a "indígenas de Egesta”. Traducción de María Cruz Herrero Ingelmo (1994).

7. D. S., 10, 23, 1, narra la guerra que enfrentó a estos dos pueblos y señala que Dorieo prestó ayuda a los crotoniatas en su conquista de la ciudad de Síbaris, lo que permite concluir que los "indígenas de Egesta”, a los que hace referencia Pausanias, defendían la ciudad.

8. Es la fecha tradicionalmente aceptada, aunque no existe plena unanimidad al respecto. Sirva, para demostrarlo, la propuesta de Barceló y Hernández de la Fuente (2014, pp. 149-150), quienes sitúan el acontecimiento en torno al 555 a. C., poco después de la primera expulsión del tirano ateniense Pisístrato.

9. Hdt., 5,71 explica que, antes de las reformas de Clístenes (508 a. C.) en Atenas, las naucrarías eran los distritos geográficos del Ática y estaban comandados por un prítano. Estos, cuando era pertinente, gobernaban la ciudad. Frente a la información herodotea, Valdés Guía (2002) concluye que los prítanos constituirían un consejo dentro del Areópago. 
10. Un análisis más profundo de la configuración de la liga del Peloponeso: Cawkwell (1993, pp. 364-376). Acerca del uso de la liga como protección frente a ataques hilotas, véase Yates (2005, pp. 65 76). Para ahondar en la protección que la liga podría brindar frente a Argos, sirvan Baltrusch (1994, pp. 19-30); Lévy (2003, pp. 219-237). quedó, en consecuencia, maldita por el sacrilegio cometido (Sierra Martín, 2014, p. 68). Esta supuesta maldición sirvió de pretexto para su expulsión de Atenas por los Pisistrátidas y, a comienzos de la Guerra del Peloponeso, dar sustancia al ultimátum espartano que conminaba a los atenienses a desterrar a los malditos (en referencia a Pericles, Alcmeónida por vía materna).

Años después, en el 548 a. C., con un régimen tiránico ya implantado en Atenas, se declaró un incendio en Delfos que necesitó de la ayuda económica de diferentes grupos oligárquicos griegos para su reconstrucción (Scott, 2015, pp. 129-156). La circunstancia se presentó como una excelente oportunidad para granjearse el favor de la pitia y los Alcmeónidas la supieron aprovechar para levantar un suntuoso templo, en cuya fachada occidental se mostraba al mismo Apolo llegando a Delfos con la ayuda de un puñado de ciudadanos atenienses (Zahrnt, 1989, pp. 297-300). La noble familia logró situar a Atenas en el centro de la historia délfica y, además, consiguió la protección del colegio sacerdotal del santuario, que no olvidaría la asistencia prestada: mediante la construcción de este lujoso recinto, los Alcmeónidas consiguieron que todas las delegaciones espartanas destinadas en Delfos recibieran de la sacerdotisa la orden expresa de "liberar Atenas" (Hdt., 5, 63, 1) de los tiranos.

El mandato délfico sirvió de perfecta excusa para que Cleómenes volviera su mirada a Atenas. La verdadera razón para que, en el año 512 o 511 a. C., el diarca orquestara una primera acción bélica contra la polis ática tendría, sin embargo, tintes más políticos que religiosos. El fortalecimiento de una tiranía como la de los Pisistrátidas atenienses podría haber hecho saltar las alarmas en Esparta, una ciudad con un peculiar sistema sociopolítico que recientemente (aproximadamente a mediados del siglo VI) se había convertido en la polis hegemónica del Peloponeso y que, para finales de ese siglo, aún necesitaba consolidar su liderazgo sobre la liga homónima que se había configurado tras la guerra entre espartanos y arcadios a finales del Arcaísmo griego, una conglomerado de alianzas que, en primera instancia, habría servido a Esparta para protegerse tanto de las intermitentes revueltas de sus hilotas como de potenciales ataques de Argos, Estado tradicionalmente hostil ${ }^{10}$. Precisamente, bajo el primer ataque de Cleómenes sobre Atenas podría subyacer la tentativa, por parte del agíada, de añadir un próspero (aunque lejano) miembro a la alianza encabezada por Esparta (Fornis, 2016, p. 102) y alejarlo de la peligrosa Argos. Los espartanos tampoco debieron de ver con buenos ojos los acercamientos de los tiranos atenienses hacia el Imperio persa (Murcia Ortuño, 2017, p. 139). En cualquier caso, el diarca utilizó el pretexto del mandato de Apolo pítico para dirigir una primera ofensiva contra Atenas. Nos lo cuenta Heródoto $(5,63,2-4)$ :

Los lacedemonios, al ver que una y otra vez recibían el mismo encargo, mandaron a Anquimolio, el hijo de Aster [...], a la cabeza de un ejército, con la misión de echar de Atenas a los Pisistrátidas [...]: los espartanos ponían la causa de los dioses [...]. De modo que enviaron a Anquimolio con naves, por mar. El tocó tierra en Falero, e hizo desembarcar a su ejército, pero los Pisistrátidas, que ya se habían enterado de la cosa, requirieron ayuda de Tesalia [...]. Los Pisistrátidas [...] mataron a muchos lacedemonios, entre ellos a Anquimolio, y forzaron a los supervivientes a reembarcarse en sus naves.

El fracaso de la tentativa no desmoralizó a Cleómenes quien, al año siguiente (510 a. C.) y blandiendo los oráculos délficos (Forrest, 1968, pp. 86-87), dirigió de nuevo su ejército contra Atenas, en esta ocasión por tierra y con el propio diarca al frente. Siguiendo la narración de Heródoto, "Cleómenes alcanzó los arrabales de Atenas y encerró, con la ayuda de aquellos atenienses que deseaban verse libres [de la tiranía], a los tiranos dentro del muro pelasgo" (Hdt., 5, 64, 2). El historiador concluye su exposición del segundo ataque de Cleómenes sobre Atenas destacando que, de 
manera prácticamente casual, los hijos de los Pisistrátidas cayeron prisioneros en manos espartanas. Los tiranos, con Hipias a la cabeza, hubieron de partir al exilio para que los lacedemonios liberasen a sus cautivos. Así fue cómo Esparta consiguió derrocar la tiranía de la pujante Atenas.

Lejos de apartarse de la política ateniense, Cleómenes no hizo sino enredarse más en ella. Al final de la tiranía en Atenas le siguió la lucha entre dos facciones aristocráticas por la consecución del arcontado, la más alta magistratura ateniense: de una parte, los que apoyaban al alcmeónida Clístenes, y, de otra, aquellos en favor de Iságoras, quien venció en las elecciones del año 508 a. C. El derrotado Clístenes, con el apoyo del demos ateniense, decidió dar un golpe de Estado para hacerse con el poder, y Cleómenes fue llamado para acudir en ayuda de Iságoras, con quien había entablado relaciones de xenía (si bien existía el rumor de que el diarca se entendía con la mujer del ateniense $)^{11}$. El agíada volvió a enarbolar motivaciones religiosas y envió un heraldo a Atenas para exigir el destierro de Clístenes, como perteneciente a la familia de los Alcmeónidas y, por tanto, descendiente de aquellos que cometieron sacrilegio al asesinar a Cilón y los suyos más de cien años atrás (vid. supra). Ante la negativa, "Cleómenes se presentó en Atenas con un pequeño contingente y expulsó a setecientas familias atenienses que Iságoras le había señalado previamente" (Hdt., 5, 72, 1). También intentó disolver la Boulé o el Consejo, establecido por Solón y compuesto por quinientos miembros que actuaban como órgano supremo del Ática, ante lo que el demos ateniense se levantó contra los espartanos, quienes no tuvieron más remedio que refugiarse tras los muros de la acrópolis. El tercer golpe de Cleómenes sobre Atenas terminó en fracaso cuando los hoplitas espartiatas se vieron obligados a rendirse y a volver a su polis, al tiempo que Iságoras y sus seguidores fueron pasados por las armas.

En el año 506 a. C. tuvo lugar la cuarta intentona del rey espartano por interferir en la política ateniense. Motivado, en esta ocasión, por deseos de venganza, la intromisión tuvo también consecuencias políticas y religiosas para los lacedemonios. Un humillado Cleómenes decidió interpelar a los aliados de Esparta en aras de reunir un poderoso ejército dirigido por ambos diarcas lacedemonios con el que invadir el Ática, sin revelar a los contribuyentes el verdadero motivo. Conscientes de que la operación no suponía más que un uso personalista de la joven Liga del Peloponeso, el contingente corintio decidió abandonar la expedición cuando se encontraba en Eleusis, ya en el Ática. Posteriormente "hizo lo mismo Demarato, hijo de Aristón, que era también rey de Esparta" (Hdt., 5, 75, 1), poniendo de manifiesto las tensas relaciones existentes entre la casa agíada y la euripóntida (Scott, 2015, p. 149; Fornis, 2016, p. 103). El relato de Heródoto da cuenta de hasta qué punto el abandono de Demarato sacudió los cimientos de la legalidad espartana: tras el desplante, "en Esparta se promulgó una ley: ya no era legal que ambos reyes siguieran el ejército en una expedición" (Hdt., $5,75,2)$. La normativa alteró asimismo las prácticas de culto espartanas, según las cuales los diarcas en campaña encarnaban a los Dioscuros, Cástor y Pólux, protectores de la institución de la diarquía y del demos espartiata (Hdt., 5, 75, 3). Al permanecer, en lo sucesivo, uno de los reyes en suelo laconio en tiempos de guerra, el dogma espartano hubo de ser convenientemente modificado (Fornis, 2016: 104) ${ }^{12}$. El bochornoso espectáculo finalizó, una vez más, con la retirada del ejército de Cleómenes del territorio ateniense. La relación entre ambos diarcas no se restituiría ${ }^{13}$.

La dichostasía perpetrada por Demarato ${ }^{14}$ en Eleusis motivó que, en adelante, los miembros de la liga del Peloponeso fueran informados de las operaciones en las que sus ejércitos tomarían parte activa. Fue, efectivamente, en el enésimo empeño de Cleómenes por invadir Atenas (en el año 504) cuando entró en funcionamiento esta asamblea por primera vez, convirtiendo oficialmente a Esparta en hegemón de la alianza (Cawkwell, 1993). En esta ocasión se trató de restituir en el poder a Hipias
11. Hdt., 5, 65-69; Fornis (2016, p. 103); Murcia Ortuño (2017, p. 140).

12. La disposición religiosa espartana afirmaba que las dos casas reales lacedemonias, la Agíada y la Euripóntida, descendían de Cástor y Pólux, hijos de Tindáreo, y que cada rey gozaba de la protección de uno de los Tindáridas, de manera que el diarca que quedara en Esparta en tiempos de guerra disfrutaría de su amparo para administrar las materias indiferentes a los procesos bélicos. Cfr. Grimal (1981, p. 517); Hard (2016, pp. 567-570).

13. Un estudio que profundiza en las relaciones entre Agíadas y Euripóntidas es el de Millender (2018).

14. Carlier (1977, p. 76) sugiere que la dichostasia fue obra de la envidia sufrida por un Demarato ensombrecido por la fuerte personalidad de su colega en el trono. 
(vid. supra), el tirano pisistrátida depuesto en 510 a. C. en la segunda incursión espartana, para eliminar la herencia clisténica de la escena política ateniense, dado que las reformas que Clístenes había acometido en Atenas poco antes de su muerte en el 508/7 a. C. sentaron las bases para el posterior sistema democrático del que los atenienses disfrutaron durante los dos siglos posteriores (cfr. Arist., Ath., 21). Cleómenes apeló a su ya rutinario recurso a la religión, esta vez por partida doble. En primer lugar, el presunto soborno consumado por los Alcmeónidas a la pitia délfica fue descubierto y conocido en Esparta (Hdt., 5, 90, 1):

[...] Cuando éstos [los espartanos] se enteraron de lo que los Alcmeónidas habían tramado en referencia a la pitia, y de lo que la misma pitia había tramado contra ellos y contra los Pisistrátidas, consideraron que era un doble infortunio, pues habían expulsado de sus países a unos hombres que les eran huéspedes [...].

El diarca habría sabido utilizar en su favor el sentimiento de venganza que habría reinado en Esparta, una polis particularmente devota, al comprender que los oráculos que la conminaban a derrocar la tiranía de los Pisistrátidas estaban viciados: los atenienses, ahora bajo el mandato de descendientes de los Alcmeónidas, debían ser escarmentados. Por si esto fuera poco, Cleómenes habría sacado a la palestra unos oráculos que encontró en la expedición militar del 510 a. C. (Hdt., 5, 90, 2):

[...] Los movieron ciertos oráculos que afirmaban que, de parte de los atenienses, iban a sufrir muchos reveses, oráculos que ellos antes no conocían, pero que ahora conocieron con precisión cuando Cleómenes se los llevó a Esparta. Los oráculos, antes en posesión de los Pisistrátidas, [...] Cleómenes los había recogido de la acrópolis de los atenienses.

Los espartanos debían de ser conscientes de los sobornos que los Alcmeónidas habían ofrecido a la pitia, pues la construcción del nuevo y suntuoso templo de Apolo en el santuario no habría pasado desapercibida para una polis con unos vínculos con Delfos como Esparta. Aun así, resulta cuestionable que a un diarca con una personalidad tan fuerte como la de Cleómenes le movieran las emociones derivadas del engaño alcmeónida, del mismo modo que la revelación de unos oráculos tan alarmantes y oportunos en ese preciso momento por parte del agíada parece, cuanto menos, sospechosa. El rey espartano no tenía en mente dar una lección de moralidad a Atenas, "tan solo" subyugarla: el principio de isonomía implantado por Clístenes hubo de despertar el recelo de los lacedemonios, quienes comprendieron con rapidez que "los atenienses, si gozaban de libertad, les igualarían en poder, mientras que si los dominaba una tiranía, sería débil y se prestarían a dejarse mandar" (Hdt., 5, 91, 1). La hipótesis más plausible dibuja a un agresivo Cleómenes que no escondía su deseo de incluir a Atenas en la Liga del Peloponeso, una personificación de una facción expansionista en ciernes de la clase dominante espartiata que vería su auge en el siglo V a. C. y, especialmente, tras la victoria espartana en la Guerra del Peloponeso en el 404 a. C.; pero también debemos pensar en el agíada como una figura temerosa de perder los lazos con Apolo pítico. El sufragio del templo délfico por los Alcmeónidas consiguió que, en las décadas posteriores, Atenas alcanzara una prominencia política sobre el oráculo que la devota Esparta y, más concretamente, alguien que hacía un uso instrumental tan desmedido de la religión como Cleómenes, no podía permitir. Temiendo perder un supuesto favor del santuario délfico y esgrimiendo la captura de los documentos oraculares que presentaban a Atenas como vencedora, los espartanos dirigieron su quinta expedición al Ática con una doble finalidad: evitar el fortalecimiento de Atenas bajo un régimen antagónico y socavar su influencia sobre la pitia.

El plan de invasión, una vez más, no prosperó. La asamblea de la Liga del Peloponeso decidió, merced a la diplomacia corintia, no intervenir en Atenas para reponer un 
régimen similar al que tanto daño hizo en Corinto, la segunda ciudad más importante de la symmachía lacedemonia, bajo los Cipsélidas (Hdt., 5, 92). Las cinco campañas de Cleómenes contra Atenas entrañaron la incapacidad del diarca en su tentativa de fortalecer la alianza peloponesia. Por el contrario, Atenas continuaría reforzándose bajo un sistema político democrático que la llevaría a distanciarse cada vez más de los intereses espartanos hasta convertir a ambas poleis en antagonistas.

La fallida intervención en Atenas no capitalizó la política exterior de la Esparta de Cleómenes. Nada más dar comienzo el siglo V a. C., el dinasta recibió un oráculo délfico que le inspiró para arremeter contra la vecina $\operatorname{Argos}^{15}$, la histórica enemiga de los lacedemonios (cfr. Fornis y Domínguez Monedero, 2014) ${ }^{16}$. La ofensiva, orquestada únicamente por espartanos sin la ayuda de aliados (Cartledge, 1979, p. 128), fue todo un éxito en sus inicios: los ejércitos lacedemonio y argivo se enfrentaron en la localidad de Sepea, donde Argos perdió sobre el campo de batalla a seis mil hoplitas ${ }^{17}$. La derrota fue de tal magnitud que en la Argólide se vivió un periodo de gran inestabilidad política en el que el gobierno de la polis pasó a manos de los esclavos, dando lugar al llamado "interregno servil" (Tomlinson, 1972, pp. 91-100).

El triunfo espartano de Sepea fue rápidamente eclipsado por el sacrilegio que cometió Cleómenes inmediatamente después y que, de nuevo, nos transmite Heródoto. Tras la batalla, los supervivientes derrotados se refugiaron en el bosque sagrado de la ciudad. Para acabar con ellos, el diarca envió un heraldo al témenos, donde comenzó a nombrar a los desertores uno por uno dando a entender que su rescate había sido pagado. Cuando los argivos iban saliendo del bosque, los lacedemonios les daban muerte sin que aquellos que seguían en el bosque, debido a su espesura, se percatasen. El plan espartano se fue al traste cuando uno de los argivos suplicantes se encaramó a un árbol y vio con sus propios ojos la realidad (Hdt., 6, 79; cfr. Domínguez Monedero, 2010, p. 126). El de Halicarnaso recogió la blasfemia que, posteriormente, consumó Cleómenes (Hdt., 6, 80):

Entonces Cleómenes mandó que cada uno de los hilotas amontonara leña en abundancia alrededor del bosque; ellos obedecieron y él le pegó fuego. El bosque ya ardía, y él preguntó a uno de los desertores a cuál de los dioses pertenecía el bosque. El cual repuso: "A Argos"18. Cuando lo oyó, Cleómenes emitió un gran gemido y dijo: "iOh tú, profeta Apolo, mucho me engañaste cuando me dijiste que yo conquistaría Argos! Sospecho que ya se me ha cumplido el oráculo".

Tras enviar a buena parte de su ejército de vuelta a Esparta, Cleómenes quiso ofrecer un sacrificio en el templo argivo de Hera, quizá para resarcirse de la ofensa a los dioses que acababa de cometer. Cuando un sacerdote trató de impedírselo por su condición de extranjero, "Cleómenes ordenó a los hilotas que echaran al sacerdote del altar y que lo azotaran" (Hdt., 6, 81): un nuevo acto sacrílego del rey agíada.

Las fuentes antiguas no se ponen de acuerdo en lo que aconteció después. El relato herodoteo afirma que el diarca, tras el incidente en el templo de Hera en Argos, no intentó siquiera asaltar la indefensa ciudad y regresó a Esparta, donde sus enemigos políticos le sometieron a un juicio bajo la acusación de haber aceptado un soborno que implicase la retirada de la Argólide ${ }^{19}$. Cleómenes se defendió de sus detractores aduciendo que "creyó haber cumplido el oráculo del dios" (Hdt., 6, 82, 1) tras haber reducido a cenizas el bosque sagrado de Argos. La defensa expuesta le permitió "salir absuelto de manera muy honorable" (Hdt., 6, 82, 2).

El testimonio de Pausanias, por su parte, refiere que Cleómenes, tras la destrucción del bosque sagrado, "condujo a los lacedemonios contra Argos privado de hombres" (Paus., 2, 20, 8-9 ${ }^{20}$. En la misma línea se manifiesta el erudito Plutarco, detallando cómo
15. El oráculo, que Bury (1902) consideró auténtico, afirmaba que Cleómenes "conquistaría Argos”, según Heródoto $(6,76$, 1). De Ste. Croix (2004, p. 426) lo data en torno al 499 a. C.

16. Hay autores, notablemente Kelly (1970) que no remontan esa tradicional hostilidad mutua más atrás del siglo $\mathrm{V}$ a. $\mathrm{C}$.

17. Forrest (196o, p. 221) y Cartledge (1979, p. 129) consideran exagerada la cifra de seis mil argivos caídos. Para profundizar en la batalla, véase Hendricks (1980).

18. En referencia a Argos, el héroe epónimo de la polis: Grimal (1981, p. 46).

19. Fornis (2016, p. 105) achaca al Euripóntida Demarato de orquestar el proceso judicia contra su colega en el trono.

20. Traducción de Herrero Ingelmo (1994). 
21. Traducción de Mercedes López Salvá (1987).
"Cleómenes, el rey de los espartanos, después de haber matado a muchos argivos [...], se dirigió a la ciudad" (Plu., Mor., 245D) ${ }^{21}$. Ambas crónicas coinciden también en el resultado del asalto: las fuerzas espartanas habrían sido rechazadas por las mujeres de la ciudad, organizadas en torno a la figura de la distinguida poetisa local Telesila, que utilizó las armas ofrendadas en los santuarios argivos para pertrechar a su improvisada hueste (Tomlinson, 1972, p. 94). Como resultado de su victoria, se implantaron en Argos las Hybristika, las "fiestas de la insolencia" (Valdés Guía, 2005).

Estas últimas versiones de los hechos deben ser tomadas con extrema precaución: entre la crónica de Heródoto y las de Pausanias y Plutarco median un mínimo de cinco siglos en los que habría arraigado una tradición argiva que ensalzara la defensa de sus ciudadanos y presentara a los espartanos como sacrílegos y cobardes vencidos por "simples" mujeres. Los hoplitas espartiatas, probablemente, no habrían tenido en cuenta siquiera la posibilidad de trabar combate contra mujeres. Además, si Argos era una polis amurallada a principios del siglo V a. C. (pues Heródoto, a diferencia de Pausanias y Plutarco, no nos proporciona información a este respecto), los muros habrían supuesto un obstáculo insalvable para las tácticas militares de un Estado tan poco ducho en poliorcética como era Esparta, así como un potencial modo absurdo de morir para sus soldados que, inspirados por el célebre ideal de la bella muerte lacedemonia (Loraux, 1977), probablemente se habrían negado a perecer intentando tomar la ciudad.

El oráculo que afirmaba que Argos se arrodillaría ante Esparta, que la historiografía supone verdadero, sirvió a Cleómenes como pretexto para atacar la Argólide en el marco de las políticas imperialistas espartanas que comenzaron a finales del siglo anterior. Sin embargo, esta operación militar también resultó frustrante, habida cuenta de que la polis argiva, si bien desguarnecida y con graves problemas políticos en el horizonte, no fue tomada. El diarca consiguió salir airoso, aun así, de las acusaciones vertidas en su contra merced, una vez más, al uso de la religión, un procedimiento al que ya acostumbraba y que aporta veracidad al relato herodoteo frente a la tradición forjada por la sociedad argiva.

Hemos visto cómo la política exterior de Cleómenes, agresiva y belicosa, pese a sentar los primeros pasos de una posterior tendencia expansionista de Esparta, no fructificó a corto plazo. La Atenas democrática experimentó un fuerte desarrollo y Argos, si bien herida, no fue completamente sometida. Las campañas contra Atenas, además, habían acarreado un verdadero quebradero de cabeza para el diarca: la enemistad con su colega Demarato, el Euripóntida, cuyas relaciones no hicieron sino empeorar. En este desolador contexto, según avanzaba el siglo $\mathrm{V}$ a. C., y después del conflicto con Argos, los planes del rey aqueménida Darío I de emprender acciones bélicas contra el mundo griego comenzaron a tomar forma mediante el envío de embajadas a las diferentes poleis helenas ${ }^{22}$. Mientras algunos Estados rehusaron firmemente someterse al Imperio persa ${ }^{23}$, otros acogieron sin reparos a los dignatarios (los estados llamados medizantes). Tal fue el caso de Egina, isla de vital importancia estratégica situada a escasos kilómetros de su enemiga Atenas que, amenazada por su posible uso como base naval aqueménida, solicitó la ayuda de Esparta para persuadir a los eginetas de cambiar de opinión, mediante la fuerza si era necesario.

Heródoto nos cuenta que, cuando el diarca Cleómenes acudió solo, sin su homólogo Demarato, a la llamada de Atenas, los eginetas rehusaron las exigencias espartanas, argumentando que ambos reyes debían estar presentes. Demarato había instruido a los habitantes de Egina sobre la normativa espartana que revestía de oficialidad únicamente a las empresas encabezadas por ambos diarcas para que pudieran defenderse de las acusaciones de Cleómenes. Desde entonces, el ambicioso gobernante adoptó una postura irreconciliable hacia su colega en el trono (Hdt., 6, 50). Parece 
que Demarato, con su autoridad regia en entredicho ante la larga sombra del agíada, buscaba restablecer el antiguo derecho de los diarcas de dirigir las campañas militares conjuntamente, pues su derogación solo habría contribuido a incrementar el prestigio político de su rival (Carlier, 1977, p. 79; Fornis, 2016, p. 107).

La "deslealtad" de Demarato terminó por colmar la paciencia de Cleómenes, quien, de vuelta en Esparta, decidió urdir una conspiración para deponer al Euripóntida. Fiel a su modus operandi, Cleómenes decidió involucrar al oráculo de Delfos en la confabulación y sobornó a la sacerdotisa de Apolo para que confirmase, en respuesta a una pregunta formulada por otro participante del complot, que Demarato no poseía linaje real (Scott, 2015, pp. 149-150). La subida al trono de Demarato (c. 515 a. C.) estuvo ya acompañada de polémica, dado que existía la sospecha, entre los espartiatas, de que no descendía realmente de su predecesor Aristón, una materia ante la que los espartanos parecían mostrarse particularmente susceptibles (cfr. Murcia Ortuño, 2017, pp. 149-150). Al mismo tiempo, Cleómenes buscó un sustituto para el trono euripóntida que no supusiera un problema a sus ambiciones expansionistas, para lo cual sirvió perfectamente Leotíquidas, primo y enemigo declarado de Demarato ${ }^{24}$, quien se convertiría en Leotíquidas II.

La conspiración surtió el efecto deseado por Cleómenes. Los oráculos emitidos por Delfos provocaron rápidamente la deposición de Demarato, que hubo de exiliarse en la corte del rey persa Darío mientras Leotíquidas se erigía en un diarca plegado a la voluntad del Agíada. Los dos reyes espartanos se dirigieron a Egina donde, esta vez sí, Cleómenes consiguió imponer sus condiciones a los eginetas: "diez hombres de la clase más alta tanto por dinero como por linaje" serían "custodiados por los atenienses, los peores enemigos de los eginetas" (Hdt., 6, 73, 2). El proyecto de Cleómenes tuvo un exitoso efecto a medio plazo, pues la medida tomada contra Egina resultó en una posición de neutralidad de la medizante polis cuando comenzó la primera guerra médica, lo que privó al Imperio persa de una magnífica posición naval a las puertas del Ática que probablemente habría cambiado el curso de la historia (De Ste. Croix, 2004, p. 428).

Las preocupaciones de Cleómenes parecían haberse esfumado con la desaparición de su mayor rival de la escena política lacedemonia gracias al empleo fraudulento del oráculo délfico. Desgraciadamente para el agíada, en el mismo año el soborno ofrecido al colegio sacerdotal del santuario salió a la luz y la treta fue descubierta. La sacerdotisa Perialo, cuyo nombre ha recibido el dudoso honor de pasar a la posteridad por este acontecimiento, fue inmediatamente relevada de su cargo ${ }^{25}$. Demarato no recuperó su posición en el trono euripóntida de Esparta, pero Cleómenes terminó huyendo de su patria. No sería de extrañar que, entre las causas que le llevaron a abandonar la polis, pesara de forma destacada el hecho de que los espartiatas no perdonarían un acto sacrílego de la envergadura de un soborno al oráculo de Delfos, como ya se demostró en la respuesta que Esparta aplicó sobre Atenas en el año 510 a. C. cuando se desveló el cohecho en el que incurrieron los Alcmeónidas (vid.supra). El exilio fue el único camino posible para una figura que había utilizado el recurso a la religión de forma abusiva, presentándose siempre como leal seguidor de las prescripciones de los dioses, tras destaparse la manipulación ejercida sobre el santuario panhelénico más influyente del momento en una cuestión tan relevante como la veracidad en torno a la legitimidad de uno de los reyes de Esparta.

Tras un breve periplo por Tesalia, Cleómenes se estableció en la vecina Arcadia, en la esfera de influencia de los lacedemonios desde el siglo VI a. C. donde, según la información que nos transmite Heródoto, "intentó levantar a los arcadios contra Esparta" (Hdt., 6, 74, 1). Cuando los espartiatas se percataron del peligro que representaría
24. Un desamor habría causado tal animadversión entre Leotíquidas y Demarato (Hdt., 6, 65).

25. Quizá la pitia más conocida de la historia del santuario: Hdt., 6, 66, 2. 
26. Los espartiatas eran conocidos por su moderación en el consumo de vino: Cartledge (2009, p. 88).

27. Así Cartledge (1979, pp. 130132); Fornis (2016, pp. 108-109); Murcia Ortuño (2017, pp. 152-153). el levantamiento de una Arcadia unida, permitieron volver al otrora diarca "en las mismas condiciones bajo las cuales él les había gobernado" (Hdt., 6, 75, 1). Cleómenes volvió a Esparta, donde acontecería su final (Hdt., 6, 75, 2-3):

Inmediatamente después de su regreso se volvió loco, una enfermedad de la cual ya antes había dado algún indicio. Porque cada vez que encontraba a un espartano le atizaba un bastonazo en el rostro. En vista de que lo hacía, y de que lo hacía cada vez más, sus allegados lo ataron a un cepo. Él, atado, cuando vio que el guardián estaba solo, que los demás se habían ido, pidió un cuchillo [...]. Y su guardián [...] acabó dándoselo. Cuando lo tuvo en sus manos, Cleómenes empezó a punzarse: empezando por los muslos se hería a lo largo del cuerpo, de abajo arriba: luego las caderas y las ijadas, hasta llegarse al vientre, que se trinchó por entero. Y así fue como murió.

Así habría perecido el dinasta, según la versión oficial lacedemonia que recoge el historiador de Halicarnaso. La presunta locura de la que adolecía Cleómenes tuvo, en el devoto mundo griego, varias explicaciones. Los argivos, dolidos aún de su derrota en Sepea, achacaron la demencia del rey espartano a una represalia divina frente al sacrilegio cometido en el bosque sagrado de Argos y en el templo de Hera de su ciudad. La tradición ateniense vinculó la enfermedad mental con la tala del témenos de Deméter y Perséfone en Eleusis en el curso de una de las campañas que los espartanos acometieron contra Atenas. El resto del mundo griego, en su mayoría, lo achacó al soborno de la pitia en el asunto de Demarato. La versión espartana fue quizá la más compasiva para con quien fuera su líder, al formular como diagnóstico el gusto de Cleómenes por consumir vino a la manera bárbara, esto es, sin mezclar con agua, costumbre que habría adquirido tras la visita de una embajada escita a Grecia (Hdt., 6, 84).

Heródoto muestra, durante toda su narración, cierta hostilidad ante el personaje de Cleómenes. La historia que nos ofrece en relación con su muerte está imbuida de un tono irónico: el diarca, que esgrimió argumentos religiosos en todos los actos de su política exterior, pereció exactamente debido a motivos de la misma naturaleza. Por ello sería prudente desconfiar de la crónica herodotea y contemplar la posibilidad de que, una vez descubierta la conjura que implicaba a la realeza espartana y al oráculo de Delfos, la sociedad lacedemonia elaborase un relato que asignara a Cleómenes un destino poco propio de un descendiente de Heracles, como podría ser el suicidio derivado de un trastorno psíquico por intoxicación etílica continuada, que bien podría pasar por excusa ante el resto de la Hélade ${ }^{26}$.

El veredicto respecto a la enfermedad de Cleómenes no puede ser más que hipotético. Parte de la historiografía moderna está de acuerdo con Heródoto en atribuirle problemas relacionados con una posible esquizofrenia paranoide (Forrest, 1968, p. 93). Aun así, el sector más amplio de la doctrina se inclina por enmarcar la muerte de este polémico personaje dentro de las intrigas políticas de la clase dominante espartiata ${ }^{27}$. Lo cierto es que resulta difícil de creer que la locura se apoderara paulatinamente, como Heródoto sugiere, de un individuo que en la última década del siglo VI a. C. lideró cinco expediciones contra Atenas. El fracaso de la cuestión ateniense de Cleómenes no es óbice para suponer que el diarca se encontraba en plenas facultades mentales, habida cuenta de la severa derrota que el ejército espartano que comandó en Sepea infringió a los argivos solo unos pocos años antes de su muerte.

Sí es seguro que con la figura de Cleómenes se da forma a lo que, con el tiempo, se convertirá en una facción de la clase dirigente espartana proclive al imperialismo opuesta a la rama que veía con reticencias la salida de Esparta fuera de la esfera política del Peloponeso. Fue un hombre de extrema ambición cuyos nuevos planteamientos 
políticos chocaron frontalmente con los preceptos tradicionales de los orgullosos espartanos que rechazaban el culto a la personalidad (X., Lak. Pol., 1) y la injerencia en lugares tan lejanos como el Ática, en una polis con recurrentes levantamientos de hilotas. El estratégico oportunismo del que hizo constante gala al utilizar convenientemente, por una parte, la célebre piedad religiosa de los espartiatas en su beneficio $\mathrm{y}$, por otra, amenazar la integridad de su patria al confraternizar con los subyugados arcadios, convirtió a Cleómenes en un peligro para la propia Esparta que trató de engrandecer y donde, con toda seguridad, había forjado enemigos a lo largo de su reinado. En este sentido, cabe recordar que los partidarios del depuesto Demarato habrían encontrado una gran satisfacción al eliminar a su máximo adversario político.

La solución para Esparta podría haber pasado por el asesinato político, del que se podría acusar no solo a seguidores de la rama euripóntida con ansias vengativas, sino también a actores sociopolíticos interesados en mantener el conservadurismo en la polis lacedemonia frente al inquietante expansionismo al que los espartanos se estaban abriendo. En cualquier caso, la tesis tendente al regicidio no es más que una mera especulación bajo la que subyace el desconocimiento y la confusión que rodean a la muerte del líder espartiata, sucedido en el año 488 a. C. por su hermanastro Leónidas ${ }^{28}$. Víctima de las intrigas internas espartanas o de la demencia, provocada bien por la ingesta de alcohol, bien por castigo de los dioses, la muerte de Cleómenes es uno de los enigmas de la historia de la antigua Grecia. Ególatra paranoico o brillante estadista, su turbulento reinado, pese a los fracasos, aseguró el dominio de Esparta en el Peloponeso y puso los cimientos de la rivalidad con Atenas que, cinco décadas después de su desaparición, desembocaría en el conflicto que devastó la Hélade, al tiempo que dejaba en evidencia los réditos políticos que suponía una óptima manipulación de la religión.
28. Harvey (1979) juega con la posibilidad de que el célebre Leónidas I, defensor del desfiladero de las Termópilas ante el Imperio persa en el año 480 a. C., formara parte del plan que terminó con la vida de Cleómenes. 


\section{Q Bibliografía}

" Balasch, M. (Trad.). (1999). Heródoto: Historias. Madrid: Cátedra.

"Baltrusch, E. (1994). Symmachie und Spondai. Untersuchungen zum griechischen Völkerrecht der archaischen und klassischen Zeit (8.-5. Jahrhundert v. Chr.). Berlin: De Gruyter.

" Barceló, P. y Hernández de la Fuente, D. (Eds.). (2014). Historia del pensamiento político griego. Teoría y praxis. Madrid: Trotta.

" Bonnechère, P. (2013). La "corruption" de la pythie chez Hérodote dans l'affaire de Démarate (VI, 6o-84). Du discours politique faux au discours historique vrai. DHA, 8, 305325.

” Braccesi, L. (1999). L'enigma Dorieo. Roma: “L’Erma” di Bretschneider.

»Bury, J. B. (1902). The Epicene Oracle Concerning Argos and Miletus. Klio, 2, 14-25.

» Carlier, P. (1977). La vie politique à Sparte sous le règne de Cléomène ler. Essai d'interprétation. Ktèma, 2, 65-84.

" Cartledge, P. (1979). Sparta and Lakonia. A Regional History. 1300 to 362 BC. Nueva York: Routledge.

" Cartledge, P. (2009). Los espartanos. Una historia épica. Barcelona: Ariel.

" Cawkwell, G. (1993). Sparta and her Allies in the Sixth Century. CQ, 43, 364-376.

»De Ste. Croix, G. E. M. (2004). Herodotus and King Cleomenes I of Sparta. En D. Harvey y R. Parker (Eds.), Athenian Democratic Origins and Other Essays (421-440). Oxford: Oxford University Press.

»Domínguez Monedero, A. J. (2010). Destrucción de la naturaleza y castigo divino: Cleómenes de Esparta y el bosque sagrado de Argos. En S. Montero y M. C. Cardete (Eds.), Naturaleza y religión en el mundo clásico. Usos y abusos del medio natural (125-142). Madrid: Signifer.

"Fornis, C. (2016). Esparta. La historia, el cosmos y la leyenda de los antiguos espartanos. Sevilla: Universidad de Sevilla.

» Fornis, C. y Domínguez Monedero A. J. (2014). El conflicto entre Argos y Esparta por la Tireátide y el culto a Apolo Piteo. Gerión, 32, 79-103.

» Forrest, W. G. (1960). Themistocles and Argos. CQ, 10, 221-240.

»Forrest, W. G. (1968). A History of Sparta. Londres: Hutchinson.

» Grimal, P. (1981). Diccionario de mitología griega y romana. Barcelona: Labor.

» Hansen, M. H. y Nielsen, T. H. (Eds.). (1994). An Inventory of Archaic and Classical Poleis. Oxford: Oxford University Press.

» Hard, R. (2016). El gran libro de la mitología griega. Madrid: La esfera de los libros.

»Harvey, D. (1979). Leonidas the Regicide? Speculations on the Death of Kleomenes I. En G. W. Bowersock et al. (Eds.), Arktouros. Hellenic Studies presented to Bernard M. W. Knox on the occasion of his 65th birthday (253-260). Berlin: De Gruyter.

» Hendricks, I. H. M. (1980). The Battle of Sepeia. Mnemosyne, 33, 340-346.

» Herrero Ingelmo, M. (1994). Pausanias. Descripción de Grecia. Madrid: Gredos.

» Huxley, G. L. (1962). Early Sparta. Londres: Faber. 
" Huxley, G. L. (1983). Herodotos on Myth and Politics in Early Sparta. Proceedings of the Royal Irish Academy, 83, 1-16.

» Kelly, T. (1970). The Traditional Enmity between Sparta and Argos. The Birth and Development of a Myth. American Historical Review, 7, 971-1003.

"Lévy, E. (2003). Sparte: histoire politique et sociale jusqu'à la conquête romaine. Paris: Seuil.

" Loraux, N. (1977). La 'belle mort' spartiate. Ktèma, 2, $105-120$.

"López Salvá (1987). Plutarco. Obras morales y de costumbres. Madrid: Gredos.

》 Malkin, I. (1987). Religion and Colonization in Ancient Greece. Leiden: Brill.

» Millender, E. G. (2018). Kingship: The History, Power, and Prerogatives of the Spartans' 'Divine' Dyarchy. En A. Powell (Ed.). A Companion to Sparta (452-479). Hoboken: Wiley Blackwell.

» Murcia Ortuño, J. (2017). Esparta. Madrid: Alianza.

"Nafissi, M. (2010). The Great rhetra (Plut. Lyc. 6): A Retrospective and Intentional Construct?. En L. Foxhall et al. (Eds.). Intentionale Geschichte. Spinning Time in Ancient Greece (89-119). Stuttgart: Steiner.

"Nafissi, M. (2018). Lykourgos the Spartan 'Lawgivwer'. Ancient Beliefs and Modern Scholarship. En A. Powell (Ed.). A Companion to Sparta (93-124). Hoboken: Wiley Blackwell.

»Scott, M. (2015). Delfos. Historia del centro del mundo antiguo. Barcelona: Ariel.

"Sierra Martín, C. (2014). La 'edad de los tiranos': una aproximación a las ambigüedades de la tiranía arcaica. Gerión, 32, 57-77.

"Tomlinson, R. A. (1972). Argos and the Argolid. From the End of the Bronze Age to the Roman Occupation. Londres: Routledge.

》Valdés Guía, M. (2002). Areópago y prítanos ton naukraron: crisis política a finales del s. VII a. C. (de Cilón a Solón). DHA, 28, 65-101.

"Valdés Guía, M. (2005). La batalla de Sepea y las Hybristika: culto, mito y ciudadanía en la sociedad argiva. Gerión, 23, 101-114.

"Von Stauffenberg, A. G. S. (1960). Dorieus. Historia, 9, 181-215.

"Yates, D. C. (2005). The Archaic Treaties between the Spartans and Their Allies. CQ, 55, 65-76.

》 Zahrnt, M. (1989). Delphi, Sparta und die Rückführung der Alkmeoniden. Zeitschrift für Papyrologie und Epigraphik, 76, 297-307. 
